\title{
Prophylatic treatment of migraine and migraine clinical variants with topiramate: an update
}

This article was published in the following Dove Press journal:

Therapeutics and Clinical Risk Management

14 August 2009

Number of times this article has been viewed

\author{
Sergio Carmona' \\ Osvaldo Bruera ${ }^{1,2}$ \\ 'Department of Neuro-otology \\ and Pain and Headache, Instituto \\ de Neurociencias de Buenos Aires \\ INEBA, Buenos Aires, Argentina; \\ 2Department of Pain and Headache, \\ Fundación Favaloro, Buenos Aires, \\ Argentina
}

\begin{abstract}
Migraine and migraine variants are common, chronic and incapacitating neurovascular disorders with a high impact on health resources. There is an extensive evidence base provided by double-blind, placebo-controlled trials showing that topiramate is a safe, effective and well tolerated drug in the management of migraine and its variants, being especially promising in the management of migraine-vertigo syndrome. Models both in the US and the UK have also shown that it offers a cost benefit when direct and indirect costs are evaluated, by reducing work loss, improving quality of life and reducing the use of increasingly scarce health resources.

Keywords: migraine, migraine prophylaxis, topiramate, quality of life, basilar migraine, cluster headache, vestibular migraine
\end{abstract}

Migraine is a chronic neurological disorder characterized by a throbbing cranial pain that typically lasts from 4 to 72 hours. It is a common, chronic, incapacitating neurovascular disorder, characterized by recurrent attacks of severe headache, and associated autonomic symptoms, eg, nausea, sensitivity to light and noise, and, in some patients, an aura involving neurologic symptoms.

\section{Clinical manifestations}

Migraine can be divided into two major subtypes:

Migraine without aura (MOA) is a clinical syndrome characterized by headache with specific features and associated symptoms.

Migraine with aura (MA), previously called classic or classical migraine, ophthalmic, hemiparesthetic, hemiplegic or aphasic migraine or complicated migraine, is primarily characterized by the focal neurological symptoms that usually precede or sometimes accompany the headache.

A combination of features is required for the diagnosis, but not all features are present in every attack or in every patient.

\section{General comments}

MOA is the commonest subtype of migraine. It has a higher average attack frequency and is usually more disabling than MA.

In approximately $15 \%$ of patients, migraine attacks are usually preceded or accompanied by transient focal neurologic symptoms, which are usually visual; such patients have MA.
Correspondence: Sergio Carmona Instituto de Neurociencias de Buenos Aires INEBA, Guardia Vieja 4435, CI I92AAW, Buenos Aires, Argentina Email scarmona@ineba.net 
In a recent large, population-based study, $64 \%$ of patients with migraine had only MOA, 18\% had only MA, and $13 \%$ had both types of migraine (the remaining 5\% had aura without headache).

Thus, up to $31 \%$ of patients with migraine have aura on some occasions, but clinicians who rely on the presence of aura for the diagnosis of migraine will miss many cases.

MOA often has a strict menstrual relationship. In contrast to the first edition of The International Classification of Headache Disorders, the second edition gives criteria for pure menstrual migraine and menstrual-related migraine. ${ }^{1}$

Very frequent migraine attacks are now distinguished as chronic migraine $(\mathrm{CM})$ provided that there is no medication overuse. MOA is the disease most prone to accelerate with frequent use of symptomatic medication, resulting in a new headache which is termed medication-overuse headache $(\mathrm{MOH})$.

\section{MA}

The aura is the complex of neurological symptoms that occurs just before or at the onset of migraine headache. Some patients also experience a premonitory phase, occurring hours to a day or two before a migraine attack. Premonitory and resolution symptoms include hyperactivity, hypoactivity, depression, craving for particular foods, repetitive yawning and other less typical symptoms reported by some patients. They include various combinations of: fatigue, difficulty in concentrating, neck stiffness, sensitivity to light or sound, nausea, blurred vision, yawning and pallor.

The terms prodrome and warning symptoms are best avoided because they are often mistakenly used to include aura.

Most migraine auras are associated with headache, fulfilling the criteria for MOA. Migraine aura is sometimes associated with a headache that does not fulfill the criteria for MOA and, in other cases, migraine aura may occur without headache. These two subforms are also now distinguished on the second classification. ${ }^{1}$

Aura with similar features has also been described in association with other well-defined headache types, including cluster headache; the relationships between aura and headache are not fully understood.

\section{Epidemiologic data and life impact, and risk of progression caused by migraine}

In the US and Western Europe, the 1-year prevalence of migraine is $11 \%$ of the adult population overall: $6 \%$ among men and $15 \%$ to $18 \%$ among women. The disabilities associated with migraine can be severe; migraine imposes considerable burdens on the sufferer and on society as well. ${ }^{2-6}$

We find it useful to assess the severity and effects of migraine by asking about days lost at work or school as a result of migraine, as well as in performing household work or chores, or in family, social, and leisure activities. ${ }^{7,8}$

Although attacks of migraine may start at any age, the incidence peaks in early to mid-adolescence.

\section{Incidence of migraine}

Despite the abundance of studies on the prevalence of migraine, studies on the incidence of migraine are relatively few. Several reports mentioned the findings of four studies that assessed the incidence of migraine. ${ }^{7-15}$ The variation in the results of these studies are not surprising given the differences in the study populations (eg, age, geographic area), as well as in the research methods employed.

Lipton et al used the reported age of migraine onset in a prevalence survey to indirectly estimate migraine incidence. ${ }^{7,8}$ Because the study enrolled subjects aged 12 to 29 years, it did not account for migraine that begins after age 29 years and for short-duration migraine that fully remits. The study found that the incidence of MA reached a peak between ages 12 and 13 years in females (14.1 per 1000 person-years), while MOA peaked between ages 14 and 17 years (18.9 per 1000 person-years). In males, the incidence of MA peaked several years earlier (at 5 years of age; 6.6 per 1000 person-years). The earlier age of onset helps to explain why boys have a higher prevalence of migraine than girls. The peak for MOA in boys was 10 per 1000 person-years between ages 10 and 11 years. New cases of migraine were uncommon among men in their twenties. The Lipton et al studies supports the concept that migraine begins earlier in males than in females and that MOA begins earlier than MA.

Another study, by Breslau et $\mathrm{al}^{3}{ }^{3}$ assessed the incidence of migraine in a random sample of young adults (aged 21 to 30 years). The authors found that the incidence of migraine was 5.0 per 1000 person-years in men and 22.0 per 1000 person-years in women, a lower incidence than that found by Stewart et al, whose study included younger subjects.

Stang et al used a linked medical records system to estimate the incidence of migraine. ${ }^{11-13}$ Because many migraine sufferers do not consult with doctors or do not receive a medical diagnosis of migraine, one would expect this method to underestimate incidence. In this study, the average annual incidence rate for the country was 3.4 per 1000 person-years (2.9 per 1000 in women and 1.4 per 1000 in men). Among women, the incidence rates were 
lower at the extremes of age and higher among women aged 10 to 49 years, with a striking peak in women aged 20 to 29 years.

A Danish study by Lyngberg et al showed that the annual incidence of migraine in people aged 25 to 64 years was 8 per 1000 person-years ( 15 per 1000 in males and 3 per 1000 in females). ${ }^{14}$ In 2001, the incidence of migraine peaked in women aged between 37 and 44 years at a rate of 20 per 1000 person-years.

\section{Prevalence of migraine}

The prevalence of migraine has been extensively reviewed exhaustively by several authors. ${ }^{7-15}$

\section{Prevalence by age and gender}

Migraine is more common in boys than in girls before puberty. As adolescence approaches, the incidence and prevalence of migraine increase more rapidly in girls than in boys. In women, prevalence increases throughout childhood and early adult life until approximately age 40 years, after which it declines. Overall, the prevalence of migraine is highest from ages 25 to 55 years for men and women, the peak years of economic productivity, which, at least in part, explains the substantial influence of migraine on lost work time. Other studies found higher rates of prevalence. For adult populations, the estimates of migraine prevalence range from $3.3 \%$ to $21.9 \%$ for women and $0.7 \%$ to $16.1 \%$ for men.

Data on the overall prevalence of migraine and prevalence by geographic location and gender were presented in the US during 1989. The American Migraine Study I collected information from 15,000 households representative of the US population. ${ }^{7,9}$ The American Migraine Study II, which used virtually identical methodology, was conducted 10 years later. In these two very large studies, the prevalence of migraine was approximately $18 \%$ in women and $6 \%$ in men..$^{8,9}$

A recent survey by the World Health Organization (WHO) rates severe migraine, along with quadriplegia, psychosis, and dementia, as one of the most disabling chronic disorders. ${ }^{2,5}$ This ranking suggests that in the judgment of the WHO, a day with severe migraine is as disabling as a day with quadriplegia. For this reason migraine is a common disabling primary headache disorder and epidemiological studies have documented its high prevalence and high socio-economic and personal impacts. It is now ranked by the World Health Organization as number 19 among all diseases in the general population as world-wide benign disease causing disability.

\section{Burdens of migraine}

Migraine is a disabling disorder that affects individuals, their families, and society.

Here we review the burden of migraine from economic and quality-of-life perspectives. , $^{5,9,13}$

\section{Socioeconomic costs of migraine}

For fatal illness, measures of mortality are used to assess reductions in quantity of life. For nonfatal illness, direct and indirect costs are measured.

Migraine, a public health problem of enormous scope, affects both the individual sufferer and on society. The American Migraine Study II estimated that 28 million people in the US have severe migraine headaches. Nearly 1 in 4 US households includes a person with migraine. Twenty-five per cent of women in the US with migraine have 4 or more severe attacks per month; $35 \%$ experience 1 to 4 severe attacks per month, while $38 \%$ experience 1 (or less than 1) severe attack per month.

A similar frequency pattern was observed for men in Argentina $^{8-14}$ (for all conditions). Costs to society were estimated to be US\$3.2 billion in 1999, and headache accounts for about one-third of over-the-counter (OTC) prescriptions. Stewart et al estimated that lost productivity due to headache (not just migraine) accounts for US\$18 billion per year. ${ }^{7-9}$

Health-related quality of life (HRQoL) and disability measures quantify the burden of migraine. Migraine episodes not only impair an individual's ability to function during an episode, but can also reduce the quality of life between episodes. The quality of life reflects an individual's assessment of general well-being and position in life within the context of culture, value systems, goals, and concerns. HRQoL is a subset that encompasses an individual's state of health, functional status (both physical and mental), and overall well-being. ${ }^{9}$

Approximately one-half of migraine sufferers are severely disabled or needed bed rest during a migraine episode. Similarly, a Canadian population survey found that one-half of migraine sufferers discontinued normal activities during episodes of migraine and nearly one-third required bed rest. More than $70 \%$ of the migraine sufferers in this survey experienced impairments in interpersonal relationships. ${ }^{8,9}$

\section{Migraine as a progressive disease}

Recent evidence suggests that a subgroup of migraine sufferers may have a clinically progressive disorder ${ }^{5,16-18}$ in which migraine episodes increase in frequency over time until the individual is in nearly constant pain. Thus, the term 
$\mathrm{CM}$ is characterized by the occurrence of headache on 15 or more days per month.

Another clue about progression comes from the finding by Welch et al that iron deposition occurs in the periaqueductal gray (PAG) area in subjects with chronic headaches. ${ }^{19}$

The PAG area is related to the descending analgesic network and is important in controlling pain and providing endogenous analgesia. It is closely related to the trigeminal nucleus. In this study by Welch et al, ${ }^{5,9,19}$ the iron levels were higher in migraine sufferers than in control subjects.

The authors propose that free-radical cell damage may lead to iron deposition, which reflects progressive neuronal damage related to recurrent migraine attacks. Perhaps repetitive central sensitization of the trigeminal neurons correlates with iron deposition in the PAG area and, therefore, frequently recurring migraine episodes may predispose a person-to-disease progression. $5,9,20$

Evidence of migraine progression also comes from a recent neuroimaging study. Kruit et $\mathrm{al}^{21}$ used a cross-sectional design to study Dutch adults aged 30 to 60 years. They showed that male subjects who experienced MA were at an increased risk of posterior circulation infarct. Additionally, women with MOA or MA were at a higher risk for deep white-matter lesions, compared with controls.

The white-matter lesions increased with episode frequency, possibly demonstrating progression of the disease..$^{22}$

In a longitudinal epidemiologic study, Scher et al, ${ }^{15}$ showed that over the course of 1 year, $3 \%$ of individuals with episodic headache (headache frequency from 2 to 104 days per year) progressed to chronic daily headache (CDH), episode frequency $>180$ days per year. ${ }^{5,15,17}$

The authors concluded that the incidence of $\mathrm{CDH}$ in subjects with episodic headache is $3 \%$ per year. In a second study, Katsarava et $\mathrm{al}^{23}$ followed 532 consecutive patients with episodic migraine ( $<15$ days per month) for 1 year. Sixty-four patients (14\%) developed chronic daily headache. . $^{5,15,19}$

Based on recent data, migraine is now understood not just as an episodic disorder, but as a chronic-episodic, and at times a chronic-progressive disorder. Ongoing research and emerging therapeutic strategies should take into account this change in the conceptual model of migraine. Preventing disease progression in migraine should be added to the existing goals of relieving pain and restoring a patient's ability to function.

\section{Transformed migraine (TM) and $\mathrm{CDH}^{9,16-18}$}

Regular use of almost any migraine medication can lead to increasingly frequent headaches. The headaches can occur daily and are related to rebound withdrawal from frequent use of the antimigraine medication. Patients experiencing this phenomenon are said to have TM and often experience episodic migraine attacks superimposed on their daily headache. The combination OTC analgesics, combination prescription analgesics, narcotic-containing analgesics, and ergotamine-containing medications are especially prone to promote the development of $\mathrm{CDH}$. Caffeine alone can cause a similar clinical picture. Experience with the triptans is limited; sumatriptan has been reported to cause rebound-withdrawal headaches. Dihydroengotamine rarely, if ever, leads to rebound headaches.

When patients are experiencing $\mathrm{CDH}$ due to rebound withdrawal, they do not usually respond to other acute or any preventive medications. Attempts to discontinue the medication that causes rebound withdrawal result in increased headache. Therefore, preventing the development of TM and $\mathrm{CDH}$ is preferable. The medications that are especially prone to cause TM are acceptable for occasional use, ie, the patient has 2 or fewer headaches per month. However, if the patient experiences migraine more frequently, use of single-ingredient, OTC or prescription medications or several medications on a rotating basis is recommended; the patient should be instructed to not use any single medication, including triptans, more than 2 days per week.

If the clinical history indicates that trigger or lifestyle issues (eg, poor sleep habits, considerable stress issues, poor nutrition) are a major issue for the patient, a short period of trying to correct these problems without instituting prophylactic medication may be reasonable, but undue delay may result in furthering the patient's already considerable disability.

Comorbidities should be considered when choosing a prophylactic agent in all the patients. Obesity, epilepsy, asthma, depression, and sleep disturbances are relatively common problems and may influence which agent is chosen. There is no literature addressing the issue of medication discontinuation. Tailoring this to the patient's individual needs is likely the best policy.

\section{Preventive therapy: goals commonly accepted indications for migraine prophylaxis ${ }^{5,24-33}$}

The indications for migraine prophylaxis include headache frequency (more than three per month) the duration and others factors presented in Table 1.

\section{Medication use}

Consensus-based principles of care will enhance the success of preventive treatment. Non-pharmacologic therapies 
Table I Preventive therapy

\begin{tabular}{ll}
\hline When & Goals \\
\hline $\begin{array}{l}\text { More than } 3 \text { days per month } \\
\text { Duration }>48 \text { hours }\end{array}$ & $\begin{array}{l}\text { Reduce frequency } \\
\text { Reduce severity } \\
\text { Acute medications ineffective }\end{array}$ \\
$\begin{array}{l}\text { Avoid headache } \\
\text { medication scalation }\end{array}$ \\
$\begin{array}{l}\text { Prolonged aura or true } \\
\text { migrainous infarction, } \\
\text { uncommon migraine } \\
\text { conditions } \\
\text { Degree of disability }\end{array}$ & Reduce risk \\
\hline
\end{tabular}

must be considered and take patient preference into consideration.

Take coexisting conditions into account, as some (comorbid/coexisting) conditions are more common in people with migraine: stroke, myocardial infarction, Raynaud's phenomenon, epilepsy, affective and anxiety disorders. These conditions present both treatment opportunities and limitations:

A. Select a drug that will treat the coexistent condition and migraine, if possible.

B. Establish that the treatments being used for migraine are not contraindicated for the coexistent disease.

C. Establish that the treatments being used for coexistent conditions do not exacerbate migraine.

D. Beware of all drug interactions.

We must take into account direct special attention to women who are pregnant or want to become pregnant. Preventive medications may have teratogenic effects. If treatment is absolutely necessary, select a treatment with the lowest risk of adverse effects to the fetus.

Moreover is very important to remember that the topiramate in high doses favors the conception.

Many migraine patients try non pharmacologic treatment to manage their headaches before they begin drug therapy or concurrently with drug therapy. Behavioral treatments are classified into three broad categories: relaxation training, biofeedback therapy, and cognitive-behavioral training (stress-management training). Physical treatment includes acupuncture, cervical manipulation, and mobilization therapy. These are treatment options for headache sufferers who have one or more of the following characteristics:

A. Patient preference for non pharmacologic interventions

B. Poor tolerance to specific pharmacologic treatments

C. Medical contraindications for specific pharmacologic treatments
D. Insufficient or no response to pharmacologic treatment

E. Pregnancy, planned pregnancy, or nursing

F. History of long-term, frequent, or excessive use of analgesic or acute medications that can aggravate headache problems (or lead to decreased responsiveness to other pharmacotherapies)

G. Significant stress or deficient stress-coping skills.

\section{Antiepileptic drugs (AEDs) in migraine, the pathophysiology of migraine, and AEDs ${ }^{25-42}$ \\ Brief overview}

Migraine is a disorder with a clear genetic basis. One of the most important aspects of the pathophysiology of migraine is the inherited nature of the disorder. It is clear from clinical practice that many patients have first-degree relatives who also suffer from migraine. Transmission of migraine from parents to children has been reported as early as the 17 th century, and numerous published studies have reported a positive family history. ${ }^{2,5,9}$

The fundamental problem with migraine is in the brain, although the exact site of initiation, whether in the cerebral cortex or brainstem, is still an issue of controversy.

Cortical spreading depression (CSD) is a slowly propagating ( 2 to $6 \mathrm{~mm} / \mathrm{min}$ ) wave of sustained neuronal depolarization, which is followed by potent, relatively long-lasting neural suppression. The aura clinical phenomenon occurring in patients with MA is very related to the electrophysiological manifestations of CSD that were observed by Leao on experimental animals. ${ }^{43,44}$ So, CSD is considered as the electrophysiological substrate of migraine aura, and many consider it necessary for the development of headache. CSD has the property of causing inflammation at the peripheral vascular component and of activating the trigeminal nucleus caudalis. ${ }^{26,27}$

After brainstem activation and/or CSD, the trigeminal system (TS) is activated, releasing neuropeptides in the brainstem and in the peripheral nerve endings at the meninges. Actions of these neuropeptides at peripheral sites (in the meninges) and within the brain play an important role in the generation and maintenance of headache pain and possibly other migraine symptoms.

Accordingly, pain generation in migraine is a consequence of cortical hyper excitability and central activation in pain-important areas, as well as the peripheral inflammation that follows. The presumable mechanism of action of AEDs in migraine is probably due to decreasing brain excitability, as 
Table 2 Medication use

\begin{tabular}{ll}
\hline Use & Considering \\
\hline $\begin{array}{l}\text { Evidence-based efficacy } \\
\text { Initiate with the lowest effective }\end{array}$ & $\begin{array}{l}\text { Topiramate among others } \\
\text { dose }\end{array}$ \\
At least 2-3 months & Re-evaluate therapy \\
Tapering after 9-12 months & Re-evaluate therapy \\
Avoid interfering medications & Avoid ergot therapy \\
\hline
\end{tabular}

well as increasing the threshold for activation in the brainstem areas important for initiating migraine.

Many AEDs has been used successfully in migraine prophylaxis. We will focus specially on topiramate. ${ }^{31-42}$

\section{Topiramate $24,25,31-42$}

Topiramate is a sulfamate-substituted monosaccharide derived from the enantiomer of fructose. Tablets are available in doses of $25 \mathrm{mg}, 100 \mathrm{mg}$, and $200 \mathrm{mg}$. In the US it is indicated as adjunctive therapy for partial-onset seizures and primary generalized tonic-clonic seizures in patients older than 2 years of age.

Topiramate, the most recent medication approved by the US Food and Drug Administration (FDA) for headache prevention, has proven to be an effective pharmacologic agent at doses ranging from 50 to $200 \mathrm{mg}$ /day. Its efficacy is similar to that of divalproex, and it has not been shown to be superior to $\beta$-blockers or tricyclic antidepressants, although clinical experience sometimes suggests that it is.

It is absorbed rapidly from the gastrointestinal tract, has a long duration of action, and renal excretion is a major route of elimination. The elimination half-life is approximately 21 hours, and it is poorly bound to plasma proteins.

Topiramate has been demonstrated to modify several receptor-gated and voltage-sensitive ion channels, including voltage-activated $\mathrm{Na}^{+}$and $\mathrm{Ca}^{2+}$ channels and non NMDA receptors that have been implicated in the pathophysiology of epilepsy and migraine. It is able to limit sustained repetitive firing, probably as a result of an interaction with the voltage-sensitive $\mathrm{Na}^{+}$channel by reducing voltage activated $\mathrm{Na}^{+}$currents. It has also been reported to modulate AMPA/ kainate receptor-mediated excitatory neurotransmission resulting in a decrease of fast excitatory neurotransmission and attenuation of focal firing. By enhancement of GABA-evoked currents, topiramate has been shown to increase the frequency of channel opening and the burst frequency without having an effect on the duration of either. The result of such action is an increase of membrane hyperpolarization, an elevated seizure threshold and a decrease of focal firing. In vitro studies have shown that the topiramate effect is not reversed by the benzodiazepine antagonist flumazenil, therefore suggesting a different binding site on the GABAA receptor or a novel site on the GABAA receptor complex than benzodiazepines. Investigations have shown topiramate to modulate both $\mathrm{N}$ - and L-type high-voltage $\mathrm{Ca}^{2+}$ channels in $\mathrm{CA} 1$ pyramidal neurons resulting in a decrease of neurotransmitter release and of sustained membrane depolarization. Topiramate weakly inhibits the carbonic anhydrase (CA) isoenzymes CA II and CAIV, which decreases excitatory neurotransmission, enhances inhibitory neurotransmission, activates a hyperpolarizing $\mathrm{K}+$ conductance and stabilizes neuronal membranes.

Topiramate is one of the only AEDs associated with weight loss. ${ }^{37}$ Adverse effects include paresthesias, cognitive deficits, nephrolithiasis, acute closed-angle glaucoma, and non-anion gap metabolic acidosis (the last three are considered idiosyncratic in nature). One and a half percent of adults exposed to topiramate during its development experienced the occurrence of kidney stones, which is approximately 2 to 4 times more than the incidence that would be expected in a population of that size. It is thought that this association results from the weak carbonic anhydrase inhibition exerted by topiramate, which also may explain the paraesthesias.

A dosage of $50 \mathrm{mg}$ twice daily has been shown to be optimal, but effects have been shown with dosages as low as $25 \mathrm{mg}$ twice daily.

Topiramate has demonstrated therapeutic clinical benefits as a preventive treatment in episodic and chronic subtypes of cluster headache and was mentioned as useful in the management of chronic migraine, basilar migraine and vestibular migraine.

\section{Benefits and cost of topiramate}

Optimizing the use of prophylactic treatment may decrease the frequency and severity of attacks thus reducing the burden of disease. In this regard, topiramate has been found to be as effective as propranolol in the prevention of migraine attacks. In the present study, a cost-minimization analysis was performed. Monthly preventive medication cost and price per migraine attack reduced were used as measures. In comparison with propranolol and flunarizine, topiramate was identified as being the most costly option for migraine prophylaxis with a monthly drug cost of US\$24.97 to 45.04 as compared with propranolol (US\$1.72 to 6.87) and flunarizine (US\$6.09 to 12.18). Current treatment options would appear to offer better value for money in achieving effective migraine prophylaxis unless additional benefits can be identified for topiramate in this patient group..$^{32,33,37}$ 
A previously published decision-analytic model assessing the clinical and economic consequences of topiramate versus no preventive treatment in migraineurs was updated with new published literature and unpublished clinical trial data. The model captured baseline migraine days, treatment discontinuation, treatment response (ie, $\geq 75 \%, 50 \%$ to $74 \%$, and $<50 \%$ reduction in migraine frequency), hours of disability, cost of preventive therapy, cost of acute treatment (pharmacy and medical service), and wages. Topiramate was associated with 29 fewer migraine-days and 78 fewer hours of disability per year, compared with no preventive treatment. The incremental cost per migraine-day averted for topiramate versus no preventive treatment was US $\$ 29$ when only direct medical costs were considered and dollar 2 when total costs were included. Model results were sensitive to baseline migraine-days, response probability, and probability of an attack being treated with a triptan. Topiramate may be a cost-effective treatment for the prevention of migraine.

\section{Topiramate and CM}

In a recent paper Silberstein ${ }^{39}$ analyzed the biggest two randomized, double-blind, placebo-controlled, multicenter trials investigating the efficacy and safety of topiramate in the treatment of patients with $\mathrm{CM}$, and their data suggest that topiramate at a dose of $100 \mathrm{mg}$ daily is effective and well tolerated.

In a US trial conducted in 46 centers, ${ }^{40}$ clinical efficacy results included a significant reduction in mean monthly rate migraine/migranous days in patients receiving topiramate compared with placebo and a mean reduction from baseline migraine days per month, compared with the placebo group. In a European study ${ }^{41}$ topiramate significantly reduced mean monthly migraine days compared with placebo and also reduced the mean number of migraine periods and attacks at all time points during the double blind phase (except week 8) compared with placebo. The difference between both studies was that patients were allowed to take acute rescue medication as usual during the European trial. Interestingly, the benefits of topiramate extended to the subgroup of patients overusing acute medications.

\section{Topiramate and basilar migraine (BM)}

$\mathrm{BM}$ is the most common migraine "variant," representing $3 \%$ to $19 \%$ of migraine in children. BM is characterized by attacks of dysarthria, vertigo, tinnitus, hypacusia, diplopia, visual symptoms simultaneously in both temporal or nasal visual fields, ataxia, decreased level of consciousness, simultaneously bilateral paraesthesias and/or followed by migraine headache.
An outpatient, double-blind, parallel-group, dose comparison study with 2 phases: pre-randomization (screening/washout and 4-week prospective baseline) and 12-week double blind (titration and maintenance), was conducted by Lewis and Paradiso ${ }^{42}$ to assess the efficacy and safety of topiramate for prophylaxis of $\mathrm{BM}$ in children and adolescents (6 to 18 years).

The results in 14 children ( 4 boys, 10 girls) who completed the double-blind phase ( 7 in the $25-\mathrm{mg}$ group and 7 in the 100-mg group) were: during the prospective baseline, the mean headache frequency of the combined group "all migraines" per month was $4.5 /$ month $(25 \mathrm{mg})$ and $4.8 /$ month (100 mg). Average duration of migraine was 5.5 hours $(25 \mathrm{mg})$ and 5.0 hours $(100 \mathrm{mg})$ and average mean pain (5-point faces scale) was 3.3 for both ( $25 \mathrm{mg} 100 \mathrm{mg})$.

Overall, $86 \%$ of patients responded with a greater than $50 \%$ reduction in migraine frequency. There were no serious adverse events.

\section{Topiramate and cluster headache $(\mathrm{CH})$}

$\mathrm{CH}$ is a well-characterized, strictly unilateral headache with cranial autonomic features and can be classified as episodic or chronic subtypes. Cluster attacks reliably are short-lived, often have a clockwise regularity, and can occur daily for weeks or months during an active cluster period. Pharmacologic treatment for this disorder can be divided into abortive and prophylactic agents. Prophylactic agents aim to quickly induce and maintain a remission.

Short-term prophylaxis may be attained with the use of steroids, ergotamine, or methysergide, but these agents are not as suitable for continuous use. Verapamil and lithium commonly are used for longer periods and other agents, such as melatonin and baclofen, also are considered useful. There have been few open label trials which proved that topiramate is a useful option to treat $\mathrm{CH}^{45-47}$

\section{Topiramate and vestibular migraine (VM)}

Even when the Internation Headache Society did not include this form of migraine variant in this last classification ${ }^{1}$ it is universally accepted in neuro-otological circles. ${ }^{48,49}$ With the establishment of the Neuhauser criteria ${ }^{50}$ there is a tool available to evaluate and to measure results of the treatment in these patients.

VM can manifest as a central or peripheral vestibular syndrome. In our opinion these are two different types of VM. In the central form the crisis and/or vestibular central signs last many our or days, ${ }^{51}$ in the peripheral one the crisis last hours, usually there are unilateral auditory symptoms and a higher risk of sudden deafness, posed the differential diagnosis with Méniére's disease..$^{52}$ One important clinical feature of this 
migraine variant is that the headache is present only in the third part of the crisis and could be previous to, simultaneous to or after the vertigo crisis. In an open trial we report successful treatment of VM patients with auditory symptoms, speculating that the inhibition of carbonic anhydrase could be useful in this subtype of VM. Central pattern forms (not peripheral) have a good response too along with the headache. ${ }^{53-55}$

The so-called paroxysmal vertigo of childhood and the paroxysmal torticollis in infancy are considered migraine equivalents. ${ }^{56,57}$

Motion sickness is a common association with vestibular migraine ${ }^{58,59}$ and there is some evidences of the genetic nature of the syndrome. ${ }^{60-62}$

\section{Effects on MA}

There are few reports on these topics. Lampl et al studied 12 patients with migraine with aura, in all 12 patients after 6 months of treatment, this did not statistically influence aura frequency or duration compared with baseline. ${ }^{63}$ Mild to moderate side effects were observed, but, consistent with previous observations, migraine frequency as well as headache intensity and duration improved statistically significantly.

\section{Doses and duration of the treatment}

In the vast majority of the trials the average dose used was $100 \mathrm{mg}$ daily and the results were tested in about the first 3 months of treatment. There is evidence that with only $50 \mathrm{mg}$ per day (considered a low dose) the results are the same as in our personal experience. We recommend an average of 9 months' duration of treatment. ${ }^{53-55}$

\section{Conclusions}

Topiramate has an extensive evidence base provided by double-blind, placebo-controlled trials, which have shown it to be a safe, effective and well tolerated drug in the management of migraine. ${ }^{64-65}$ It has also been shown to have a role in the management of $\mathrm{CM}, \mathrm{VM}$ and $\mathrm{CH}$, which represent a challenge to primary care clinicians as well as headache specialists. Studies have demonstrated that topiramate can also be effective in preventing migraine in childhood and adolescence. It has been shown in models both in the US and the UK to offer a cost benefit when direct and indirect costs are evaluated by reduced work loss, improved quality of life and reduced use of increasingly scarce health resources.

\section{Acknowledgments}

We want to express our special thanks to Mrs Marisa Cardón for her work in correcting the manuscript.

\section{Disclosures}

The authors disclose no conflicts of interest.

\section{References}

1. Headache Classification Subcommittee of the International Headache Society. Classification of Headache Disorders, 2nd ed. Cephalalgia. 2004;24(Suppl 1):1-150.

2. Goadsby PJ, Lipton RB, Ferrari MD. Migraine - current understanding and treatment. N Engl J Med. 2002;346:257-270.

3. Breslau N, Davis GC, Schultz LR, Peterson EL. Joint 1994 Wolff Award Presentation. Migraine and major depression: a longitudinal study. Headache. 1994;34:387-393.

4. Stewart WF, Linet MS, Celentano DD, Van Natta M, Ziegler D. Age and sex-specific incidence rates of migraine with and without visual aura. Am J Epidemiol. 1991;134:1111-1120.

5. Goadsby PJ. Migraine pathophysiology. Headache 2005;45(Suppl 1): S14-S24.

6. Silberstein SD. Practice parameter: evidence-based guidelines for migraine headache (an evidence-based review). Report of the Quality Standards Subcommittee of the American Academy of Neurology. Neurology. 2000;55:754-762.

7. Lipton RB, Stewart WF, Simon D. Medical consultation for migraine: results from the American Migraine Study. Headache. 1998; 38:87-96.

8. Lipton RB, Stewart WF, Diamond S, Diamond ML, Reed M. Prevalence and burden of migraine in the United States: data from the American Migraine Study II. Headache. 2001;41:646-657.

9. Lipton RB, Bigal ME. Migraine: epidemiology, impact, and risk factors for progression. Headache. 2005;45(Suppl 1):S3-S13.

10. Launer LJ, Terwindt GM, Ferrari MD. The prevalence and characteristics of migraine in a population-based cohort: the GEM Study. Neurology. 1999;53:537-542.

11. Stang PE, Yanagihara T, Swanson JW, et al. Incidence of migraine headaches: a population-based study in Olmsted County, Minnesota. Neurology. 1992;42:1657-1662.

12. Stang PE, Osterhaus JT. Impact of migraine in the United States: data from the National Health Interview Survey. Headache. 1993;33:29-35.

13. Stang PE, Sternfeld B, Sidney S. Migraine headache in a pre-paid health plan: ascertainment, demographics, physiological and behavioral factors. Headache. 1996;36:69-76.

14. Lyngberg A, Jensen R, Rasmussen BK, Jorgensen T. Incidence of migraine in a Danish population-based follow-up study [abstract]. Cephalalgia. 2003;23:596.

15. Scher AI, Stewart WF, Lipton RB. Migraine and headache: a meta-analytic approach. In: Crombie IK, editor. Epidemiology of pain. Seattle, WA: IASP Press; 1999. p. 159-170.

16. Silberstein SD, Lipton RB, Sliwinski M. Classification of daily and near-daily headaches: field trial of revised IHS criteria. Neurology. 1996;47:871-875.

17. Lipton RB, Hamelsky SW, Stewart WF. Epidemiology and impact of migraine. In: Silberstein SD, Lipton RB, Dalessio DJ, editors. Wolff's headache and other head pain. New York, NY: Oxford University Press; 2001. p. 85-107.

18. Lipton RB, Pan J. Is migraine a progressive brain disease? JAMA. 2004;291:493-494.

19. Welch KM, Nagesh V, Aurora S, Gelman N. Periaqueductal grey matter dysfunction in migraine: cause or the burden of illness? Headache. 2001;41:629-637.

20. Loder E, Biondi D. General principles of migraine management Headache. 2005;45(Suppl 1):S33-S47.

21. Kruit MC, Launer LJ, Ferrari MD, van Buchem MA. Infarcts in the posterior circulation territory in migraine. The population-based MRI CAMERA study. Brain. 2005;128(9):2068-2077.

22. Kruit MC, van Buchem MA, Hofman PA, et al. Migraine as a risk factor for subclinical brain lesions. JAMA. 2004;291(4):427-434. 
23. Katsarava Z, Schneeweiss S, Kurth T, et al. Incidence and predictors for chronicity of headache in patients with episodic migraine. Neurology. 2004;62(5):788-790.

24. Bigal ME, Lipton RB, Krymchantowski AV. The medical management of migraine. Am J Ther. 2004;11:130-140.

25. Krymchantowski AV, Bryson J, Lipton RB, Bigal ME. Neuromodulators for the treatment of headache disorders and fibromyalgia. Curr Pain Headache Rep. 2008;12:333-337.

26. Bolay H, Reuter U, Dunn AK, Huang Z, Boas DA, Moskowitz MA. Intrinsic brain activity triggers trigeminal meningeal afferents in a migraine model. Nat Med. 2002;8:136-142.

27. Casucci G, Villani V, Frediani F. Central mechanism of action of antimigraine prophylactic drugs. Neurol Sci. 2008;29(Suppl 1):S123-S126.

28. Yaldo AZ, Wertz DA, Rupnow MF, Quimbo RM. Persistence with migraine prophylactic treatment and acute migraine medication utilization in the managed care setting. Clin Ther. 2008;30:2452-2460.

29. Ferrari A, Spaccapelo L, Pinetti D, Tacchi R, Bertolini A. Effective prophylactic treatments of migraine lower plasma glutamate levels Cephalalgia. 2009;29(4):423-429.

30. Bigal M, Lipton R, Winner P, et al. Clinical markers of cardiovascular risk in migraine: association with weight change. 49th Annual Scientific Meeting. American Headache Society. June 7-11, 2007, Chicago, IL. Headache. 2007;47:Abstract 791.

31. Brandes JL. Practical use of topiramate for migraine prevention. Headache. 2005;45(Suppl 1):S66-S73.

32. Ergun H, Gulmez SE, Tulunay FC. Cost-minimization analysis comparing topiramate with standard treatments in migraine prophylaxis. Eur Neurol. 2007;58:215-217.

33. Cutrer FM, Antiepileptic drugs: how they work in headache. Headache. 2001;41(Suppl 1):S3-S10.

34. Puppe A, Limmroth V. GABAergic drugs for the treatment of migraine. CNS Neurol Disord Drug Targets. 2007;6:247-250.

35. Topiramate. Official FDA information side effects and uses. Available at www.drugs.com/pro/topiramate.html; Accessed June 10, 2009

36. Landmark CJ. Antiepiptic drugs in non-epilepsy disorders: relations between mechanisms of action and clinical efficacy. CNS Drugs. 2008;22:27-47.

37. Taylor FR. Weight change associated with the use of migraine-preventive medications. Clin Ther. 2008;30:1069-1080.

38. Brown JS, Rupnow MF, Neumann P, Friedman M, Menzin J. Cost effectiveness of topiramate in the prevention of migraines in the United States: an update. Manag Care Interface. 2006;19:31-38.

39. Silberstein SD, Diener HC, Lipton RB, et al. Epidemiology, risk factors, and treatment of chronic migraine: a focus on topiramate. Headache. 2008;48;1087-1095.

40. Silberstein SD, Diener HC, Lipton RB, Dodick DW, et al. Efficacy and safety of topiramate for the treatment of chronic migraine: A randomized, double-blind, placebo-controlled trial. Headache. 2007;47:170-180

41. Diener H-C, Bussone G, Van Oene JC, Lahaye M, Schwalen S, Goadsby PJ. Topiramate reduces headache days in chronic migraine: A randomized, double-blind, placebo-controlled study. Cephalalgia. 2007;27:814-823

42. Lewis D, Paradiso E. A double-blind, dose comparison study of topiramate for prophylaxis of basilar-type migraine in children: a pilot study. Headache. 2007;47:1409-1417.
43. Leão AA. The slow voltage variation of cortical spreading depression of activity. Electroencephalogr Clin Neurophysiol. 1951;3(3): 315-321.

44. Leão AA. Spreading depression. Funct Neurol. 1986;1(4):363-366.

45. Mathew NT, Kailasam J, Meadors L, Prophylaxis of migraine, transformed migraine, and cluster headache with topiramate. Headache. 2002;42:796-803.

46. McGeeney. Topiramate in the treatment of cluster headache. Curr Pain Headache Rep. 2003;7:135-138.

47. Cutrer FM, Baloh RW. Migraine-associated dizziness. Headache. 1992;32:300-304.

48. Baloh R. Neurotology of migraine. Headache. 1997;37:615-621.

49. Dieterich M, Brandt T. Episodic vertigo related to migraine (90 cases): vestibular migraine? J Neurol. 1992;246:883-892.

50. Neuhauser H, Leopold M, von Brevern M, Arnold G, Lempert T. The interrelations of migraine, vertigo and migranous vertigo. Neurology. 2001;56:436-441

51. Von Brevern M, Zeise D, Neuhauser H, Clarke AH, Lempert T. Acute migranous vertigo: clinical and oculographic findings. Brain. 2005;128:365-374.

52. Rassekh CH, Harker LA. The prevalence of migraine in Ménière Disease. Laryngoscope. 1992;102:135-138.

53. Carmona $\mathrm{S}$, Settecase N. Use of topiramate (Topamax) in a subgroup of migraine vertigo patients with auditory symptons. Ann N Y Acad Sci. 2005;1039:517-520

54. Carmona S. Topiramate in migraine vertigo. Proceedings of the XXIV Bárány Society Meeting. Uppsala; 2006:5.

55. Carmona S, Bruera O. Migraine-vertigo with auditory symptoms a definite subtype of migraine? Proceedings of the XXV Bárány Society Meeting, 2008. p. 173

56. Avu-Arafeh I, Russel G. Paroxysmal vertigo as a migraine equivalent in children: a population-based study. Cephalalgia. 1995;15: $22-25$.

57. Snyder CH. Paroxysmal torticollis in infancy. Am J Dis Child. 1969;117:458.

58. Drummond PD, Granston A. Facial pain increases nausea and headache during motion sickness in migraine sufferers. Brain. 2004;127: 526-534.

59. Furman JM, Marcus D. Migraine and motion sensitivity. continuun. Neuronotology. 2006;12(4):116-134

60. Oh AK, Lee H, Jen JC, Corona S, Jacobson KM, Baloh RW. Familial benign recurrent vertigo. Am J Med Genet. 2001;100:287-291.

61. Ophoff RA, Terwindt GM, Vergouwe MN, et al. Familial hemiplegic migraine and episodic ataxia type- 2 are caused by mutations in the $\mathrm{Ca}^{2+}$ channel gene CACNL1A4. Cell. 1996;87(3):543-552.

62. Baloh R, Jen J. Genetics of familial episodic vertigo and ataxia. Ann N Y Acad Sci. 2002;956:338-345.

63. Lampl C, Bonelli S, Ransmayr G. Efficacy of topiramate in migraine aura prophylaxis: preliminary results of 12 patients. Headache. 2004;44:174-177.

64. Gupts P, Singh S, Goyal V, Shuktla G, Behari M. Low dose topiramate versus lamotrigine in migraine prophylaxis (the Lotolamp study). Headache. 2007;47:402-412.

65. Lipton RB, Diamond S, Reed M, Diamond ML, Stewart WF. Migraine diagnosis and treatment: results from the American Migraine Study II. Headache. 2001;41:638-645.
Therapeutics and Clinical Risk Management

\section{Publish your work in this journal}

Therapeutics and Clinical Risk Management is an international, peerreviewed journal of clinical therapeutics and risk management, focusing on concise rapid reporting of clinical studies in all therapeutic areas, outcomes, safety, and programs for the effective, safe, and sustained use of medicines. This journal is indexed on PubMed Central, CAS,

\section{Dovepress}

EMBase, Scopus and the Elsevier Bibliographic databases. The manuscript management system is completely online and includes a very quick and fair peer-review system, which is all easy to use. Visit http://www.dovepress.com/testimonials.php to read real quotes from published authors. 